Civil Engineering

Volume 170 Issue CE5

Crossrail project: use of sprayed concrete tunnel linings on London's Elizabeth line Coughlan, Diez, Comins and Stärk
Proceedings of the Institution of Civil Engineers Civil Engineering 170 May 2017 Issue CE5 Pages 39-46 http://dx.doi.org/10.1680/jcien. 16.00026 Paper 1600026

Received 01/07/2016_Accepted 26/01/2017 Keywords: groundwater/numerical modelling/tunnels \& tunnelling

\title{
Crossrail project: use of sprayed concrete tunnel linings on London's Elizabeth line
}

1 Donal Coughlan BE, MEngSC, CEng, MIEI, MICE, MIStructE Head of Discipline, Chief Engineer's Group, Crossrail, London, UK

2 Rosa Diez BSc, MSc, DIC, FGS, CEng, MIMMM Project Director, Mott MacDonald, Croydon, UK
3 John Comins BEng, HND Construction Manager, Dragados, London, UK

$4 \quad$ Alfred Stärk Dipl.-Ing., Dr.-Ing

Chief Geotechnical Engineer, Bemo Tunnelling, Innsbruck, Austria
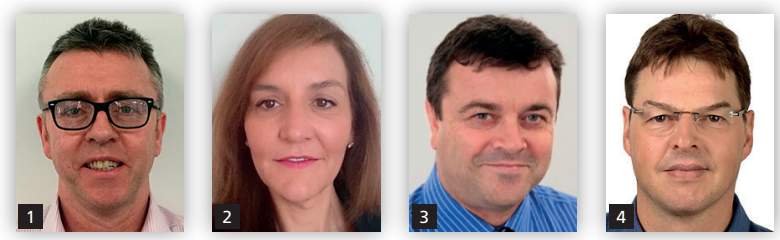

This paper discusses the use of sprayed concrete linings on the Crossrail project to deliver the Elizabeth east-west railway line across London. It describes how sprayed concrete linings have been successfully used, leading to significant programme and cost savings to the project. Sprayed concrete linings have been used to form complex station tunnel geometries, including tunnel junctions and tunnels of varying cross-section as well as a number of large cross-over caverns, shafts and adits. The design of sprayed concrete lining tunnels is discussed in detail, including how the tunnels were analysed, sized and reinforced to resist applied ground loads. The paper also describes how the technique has been successfully adopted to form the complex caverns at Whitechapel and Stepney Green cross-overs. Topics covered include construction methodology, material selection, monitoring requirements and lessons learnt for application on future projects.

\section{Introduction}

Sprayed concrete linings have been used extensively on the $£ 14.8$ billion Crossrail project to deliver the Elizabeth line eastwest across London, in particular at the central stations along the route. The technique is ideally suited to the construction of short tunnel drives with varying cross-sections, as well as the large number of tunnel junctions with non-standard and complex geometries and alignments.

Examples include the junctions between cross-passages and platform tunnels and between concourse areas and inclined escalator shafts. The technique has also been used successfully in the construction of various shafts and cross-over caverns along the route.

The new Elizabeth line stations at Bond Street, Tottenham Court Road (St. John et al., 2017), Farringdon (Gakis et al., 2015), Liverpool Street and Whitechapel have all been constructed using sprayed concrete linings (Figure 1). The shafts at Fisher Street, Mile End Park, Eleanor Street and Limmo Peninsula have incorporated sprayed concrete linings in their construction. The versatility of the technique has also been clearly demonstrated in the construction of the crossover caverns at Fisher Street, Whitechapel and Stepney Green, the geometry of which were highly complex, with spans exceeding $17 \mathrm{~m}$.

\section{Sprayed concrete lining tunnels}

Sprayed concrete lining tunnels are typically constructed by excavating the ground in short advances and progressively applying sprayed concrete to support the ground. The sprayed concrete linings of the Elizabeth line typically incorporate steel fibres in the mix to enhance the tensile capacity and ensure ductile behaviour in the concrete.

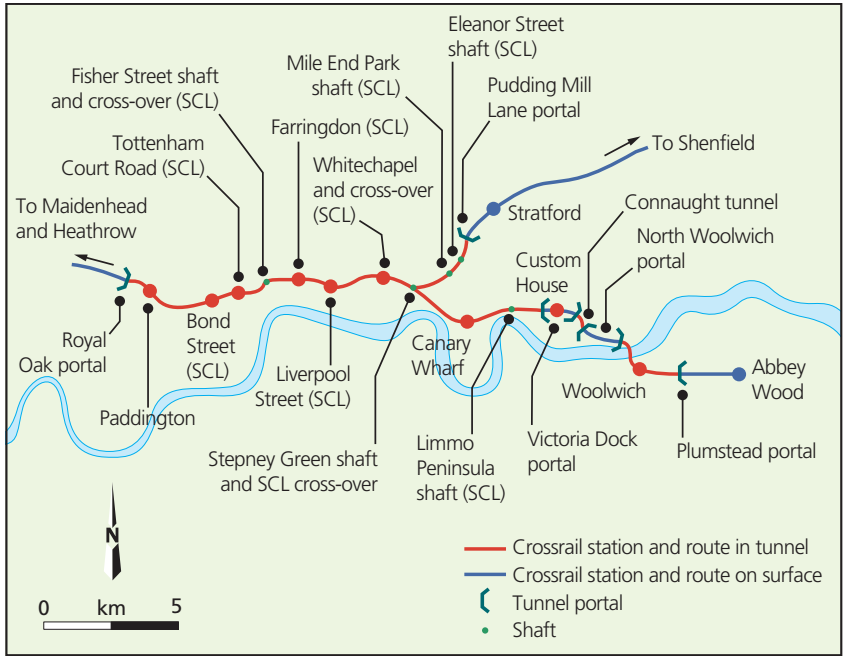

Figure 1. Plan of the central tunnelled section of London's Elizabeth line showing stations, shafts and cross-overs constructed with sprayed concrete linings (SCLS)

Following excavation of the ground, a sealing layer up to $75 \mathrm{~mm}$ in thickness is applied. This is followed by the construction of the remainder of what is referred to as the primary lining. The overall thickness of this lining is typically $300-350 \mathrm{~mm}$, although it is usually greater at tunnel junctions.

Once the primary lining has been completed for a section of tunnel, a regulating layer is then applied to the primary lining; this provides a smooth surface prior to application of a waterproofing layer. This layer prevents the steel fibres present in the primary 
lining from damaging the waterproofing. A further layer of sprayed concrete of $250-300 \mathrm{~mm}$ thickness, known as the secondary lining, is then applied followed by the application of a $50 \mathrm{~mm}$ thick concrete fire protection layer (see Figure 2).

The primary lining was designed to resist external forces due to all short-term ground loads as well as the effects of other transient loads such as compensation grouting and any surcharge loads applied at surface level during the construction works. It was also designed to resist a certain percentage of the long-term ground loading apart from hydrostatic loads, which the secondary lining was designed to resist.

The secondary lining was also designed to resist internal forces induced by its own self-weight (no compression in secondary lining), long-term ground loadings, temperature and shrinkage effects, services fixing loads and degradation of $75 \mathrm{~mm}$ of the secondary lining due to the effects of a fire in the tunnel. The lining system is therefore a double shell with both linings considered part of the permanent load-bearing structure throughout the design life of the tunnel.

The primary lining was designed with the aid of two-dimensional (2D) and three-dimensional (3D) numerical modelling techniques using the finite-difference software package FLAC, which is able to represent the non-linear behaviour of the ground and provides a reliable representation of the ground-structure interaction. 2D numerical models of selected critical sections were used to confirm the stability of the excavation and to determine the tunnel lining internal forces both in the long term and the intermediate construction stages.

Three-dimensional analyses were carried out for the largest cross-over tunnel cross-sections, for instance, where the presence of the headwall had a positive influence on the final output of the internal lining forces (Figure 3). The models included the effects of all the adjoining structures, including the appropriate surcharge loading, and made allowance for tolerances at each construction stage.

A simplification inherent in 2D modelling is the relaxation of the ground ahead of an excavation face, which is largely a 3D effect. The values used in the 2D modelling were accordingly calibrated against 3D models and data from tunnels previously constructed in London Clay. The time-dependent development of sprayed concrete strength and stiffness was also included in the models, using the strength-gain curves from the project's sprayed concrete lining specification (Crossrail, 2012) based on BS EN 14487-1 (BSI, 2005) and a relationship between the stiffness value and strength.

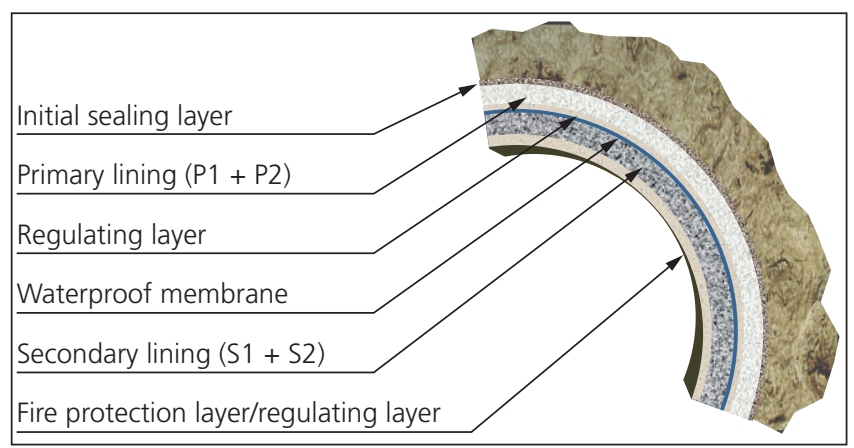

Figure 2. Typical composition of a sprayed concrete tunnel lining
Eurocode 2 (BSI, 2004) permits a reduction of the sprayed concrete lining stiffness to take account of the creep and relaxation that occurs during early-age loading before reverting to full stiffness prior to secondary lining installation. Plastic hinges were also allowed to develop, with a limit on the maximum rotation and the number permitted per cross-section. 2D and 3D computer structural models based on the centroid of the tunnel lining cross-section, allowing for required tolerances, and the application of all possible load combinations, were used to determine the secondary linings forces. For the biggest cavern cross-sections plastic hinges were also allowed to develop such that crack widths in the concrete lining due to rotation did not exceed $0.3 \mathrm{~mm}$.

Testing of all the possible products for sprayed waterproofing membranes was not able to demonstrate that they provide sufficient bond with sprayed concrete in the long term under saturated conditions and sustained loading. Therefore, the secondary lining design did not allow for full composite action between the primary and secondary linings. It was conservatively assumed that the membrane allows a full shear slip to take place between the linings. The secondary linings were also designed to provide sufficient residual capacity to resist ground and hydrostatic loads after a tunnel fire represented by the RABT-ZTV (Eureka) timetemperature fire curve (EC, 1996, 2008).

The sprayed secondary lining typically included a $50 \mathrm{~mm}$ thick final layer of plain concrete with polypropylene fibres added to provide the required fire resistance. Due to difficulties controlling the accurate thickness and profiling of this layer on some contracts, the secondary lining polypropylene layer was increased in thickness to incorporate the second layer of reinforcement where reinforcement was required. Fire testing of various secondary lining test panel configurations reflecting the fireproofing thicknesses and mix designs adopted on each contract were undertaken to demonstrate the linings' ability to resist the RABT-ZTV fire curve.

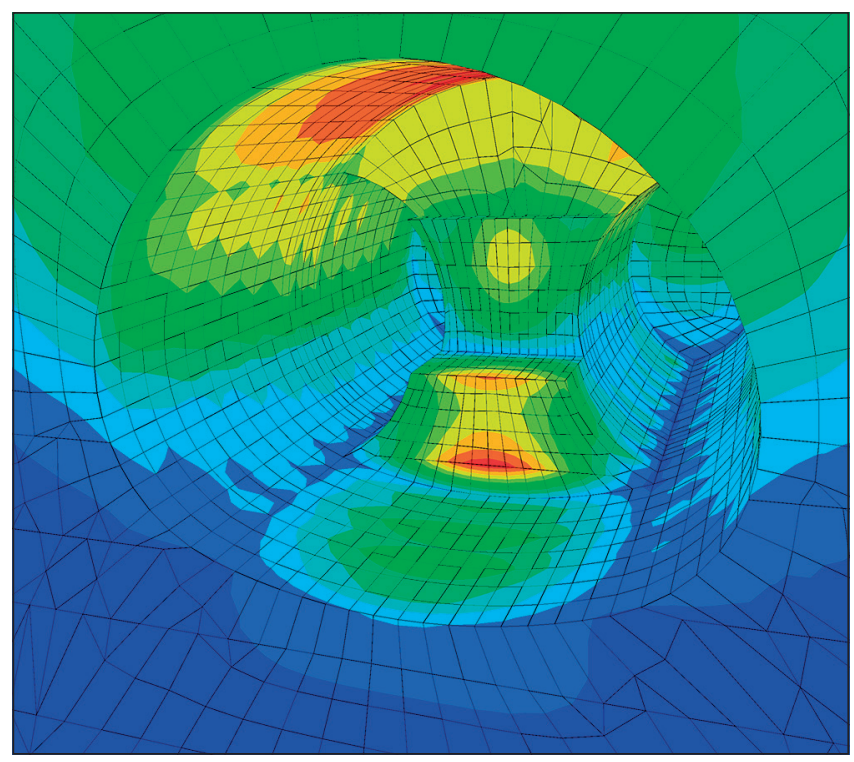

Figure 3. Three-dimensional analysis of Stepney Green cross-over primary lining during excavation to full cross-section 


\section{Design and specification}

A framework design consultant (Mott MacDonald) was responsible for the design of all the permanent sprayed concrete lining works on the Elizabeth line. However, for some contracts, the contractor appointed an independent sprayed concrete lining designer to design the primary lining in the temporary condition.

The point at which responsibility for the primary lining design switched to the framework design consultant varied between contracts. For example, on the Eleanor Street and Mile End Park shafts contract, design responsibility was transferred on completion of the primary lining sprayed concrete lining ring, whereas on the Liverpool Street and Whitechapel station tunnels contract, design responsibility was transferred on completion of the secondary lining ring.

In terms of design assurance, the framework design consultant carried out a fully independent category 3 check of the contractor's sprayed concrete lining design for the primary lining in the temporary condition, taking account of the construction sequencing. Another consultant carried out an independent category 3 check of the permanent works, including both the primary and secondary linings.

\subsection{Project requirements}

Crossrail information paper D23 on sprayed concrete linings (Crossrail, 2007) formed part of the environmental minimum requirements to the Crossrail Act 2008, imposing specific responsibilities on the client, designers and contractors. Key requirements were to ensure the sprayed concrete lining works were constructed in accordance with the design and to confirm the conditions encountered during tunnel construction agreed with assumptions made in the design.

A requirement to confirm and show the planned sequence and support requirements for the next few advances including toolbox items was met through preparation of a required excavation support sheet. This was tabled at daily meetings of the shift review group together with weekly reviews by a construction technical committee.

The meetings were attended by the contractor's team, the framework design consultant's site team and Crossrail field engineers. The sheets included a record of in-tunnel monitoring data, ground-surface monitoring including any third-party structural monitoring, trigger breaches, marked-up progress drawings and descriptions of works.

\subsection{Materials selection}

Steel-fibre-reinforced concrete was predominantly used in the construction of both the primary and secondary linings. In certain locations where the tensile stresses induced in the lining exceeded the tensile strength of the steel-fibre-reinforced concrete, additional high-tensile-steel reinforcing bars were introduced, particularly at junctions between tunnels. This reinforcement was typically located above the opening in the larger tunnel known as the 'parent' tunnel.

The concrete was typically a C32/40 mix with a steel fibre content of not less than $30 \mathrm{~kg} / \mathrm{m}^{3}$. The contractor could, however, increase the fibre content up to $45 \mathrm{~kg} / \mathrm{m}^{3}$ to ensure that sprayed concrete lining residual tensile strength criteria were met. The residual tensile strength was established through flexural beam tests in accordance with BS EN 14487-1 (BSI, 2005). The earlyage strength of the concrete mixes was regularly checked to confirm the concrete compressive strength gain was in accordance with a modified $\mathrm{J} 2$ curve as per BS EN 14487-1.

Samples of the steel-fibre-reinforced concrete mix were tested during each shift using a penetrometer or needle gun at regular time intervals over a $24 \mathrm{~h}$ period with additional core samples taken for testing at 1, 3, 7, 28 and $90 \mathrm{~d}$. Early testing to demonstrate the achievement of strength gain in the first hour after application was also undertaken to verify early reaction within the concrete and to help guide the relaxation of exclusion zones to overhead works.

At locations where reinforcement was required within an area of sprayed lining, a concrete mix was typically selected without steel fibres owing to concerns relating to poor encapsulation of the reinforcement with higher accelerator doses also being required when spraying above the tunnel axis. Cores were taken in the vicinity of the reinforcement to confirm the absence of poor encapsulation and also to confirm that delamination was not an issue where the lining was sprayed in layers.

The selection of waterproofing was dictated by the likelihood of water ingress. At Farringdon station, virtually all of the sprayed concrete lining tunnels were waterproofed using a sheet membrane with an underlying geotextile to avoid damage to the waterproofing. A similar approach was adopted at certain locations in the tunnels at Liverpool Street and Whitechapel stations. Elsewhere, a sprayed membrane up to $6 \mathrm{~mm}$ in thickness was adopted. This membrane was tested regularly through in situ bond tests to confirm adequate adhesion with the substrate.

\section{Cross-over sprayed concrete lining structures}

Cross-overs have been provided at Fisher Street, Whitechapel and Stepney Green. The Fisher Street cross-over incorporates an enlargement from each of the precast concrete segment-lined running tunnels into a trumpet-shaped cavern, a 'binocular' arrangement at either end of the caverns, and a length of conventional sprayed concrete lining tunnel for the cross-over itself with adits connecting the running tunnels (Figure 4). The size of the Fisher Street cross-over cavern at the end of the trumpet-shaped cavern underneath critical buildings led to the division of the cross-section into a binocular structure, where the secondary lining of the first sector had to be in place before the excavation of the primary lining of the second part of the binocular.

Similarly, the cross-over to the west of Whitechapel station comprises an enlargement of both running tunnels in sprayed concrete lining, caverns at either end of the cross-over and ancillary tunnels. The tunnel enlargements and caverns were also designed to accommodate both the reception and launch of the tunnel boring machines (TBMs) for the eastern running tunnels. The excavation sequence adopted for construction of the Whitechapel cross-over was dictated by the interdependence between the TBM transit and the construction of the structure, leading to a complex sequence of unusually shaped drifts and additional access adits excavated in several stages, building up to the full-size caverns. 
Crossrail project: use of sprayed concrete tunnel linings on London's Elizabeth line

Coughlan, Diez, Comins and Stärk
Two large sprayed concrete lining caverns were constructed at the Stepney Green cross-over to allow trains to access both the north-east and south-east spurs. The Stepney Green caverns, the first big cross-overs to be excavated on the project, incorporated techniques such as a double side-drift and central bench for the biggest cross-section, subsequently also used at Whitechapel, and the use of lattice girders for profile control. The lattice girders were subsequently removed following demonstration of proper profile control by the contractor and consultation with Crossrail.

A spray-applied waterproofing membrane was used throughout the Fisher Street caverns, as they were fully excavated in London Clay. In the Whitechapel and Stepney Green caverns, a spray-applied waterproofing membrane was used above invert level with a sheet membrane applied below due to the active water ingress encountered in the inverts associated with the proximity of the Lambeth Group.

\section{Stepney Green caverns}

The Stepney Green cavern primary lining was part of contractor Dragados-Sisk joint venture's eastern running tunnels contract. Work started in November 2012 and the $350-500 \mathrm{~mm}$ primary lining was completed in August 2013, with the 250-400 mm secondary lining completed in March 2016. The permanent invert slab and part of the secondary lining were constructed prior to the arrival of the TBMs from Limmo Peninsula and Pudding Mill Lane respectively.

The primary lining was constructed in two layers (P1 then P2) using steel-fibre-reinforced sprayed concrete lining followed by

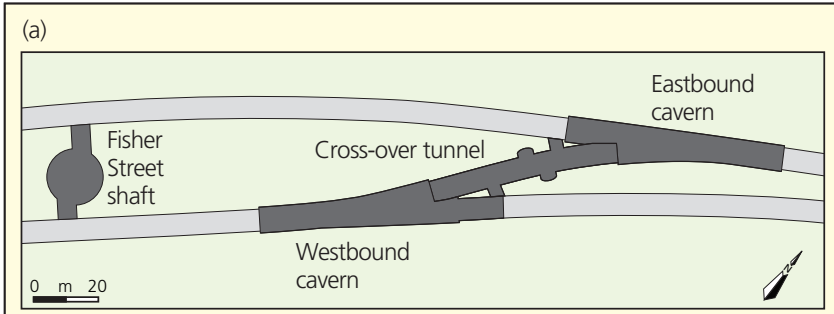

(b)

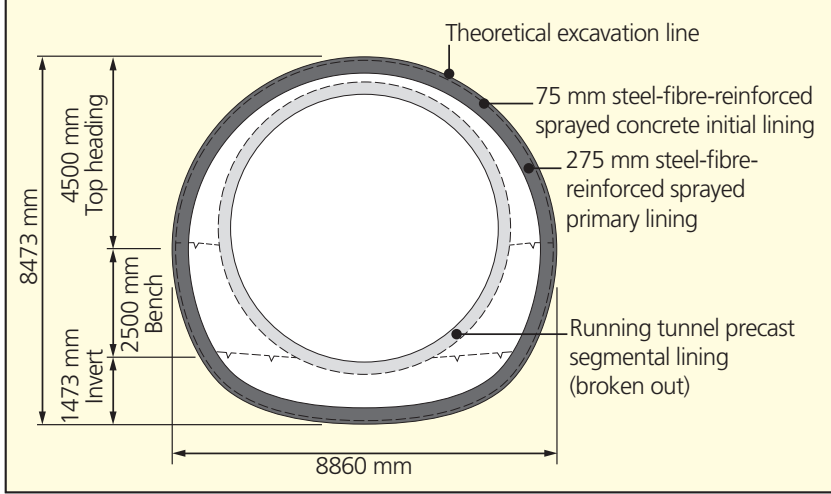

Figure 4. Fisher Street cross-over plan (a) and section (b) steel-bar-reinforced sprayed concrete lining. The caverns were excavated in stages with the face of each stage divided into top heading, bench and invert (as in Figure 4(b)).

The main ground hazard encountered during construction of the sprayed concrete lining works was the presence of high pore-water pressures in the sandy layers of the upper part of the Lambeth Group. A surface dewatering scheme comprising inclined ejectors outside the site boundaries at $8 \mathrm{~m}$ centres was developed to depressurise the groundwater within the upper part of the Lambeth Group (Black, 2017; Linde-Arias et al., 2015).

\subsection{Excavation sequence and ground support}

Three teams were mobilised in November 2012 to work the $24 \mathrm{~h} / 7 \mathrm{~d}$ shift pattern. At peak construction, over 80 staff and operatives worked at site on each shift. The eastbound launch adit, situated wholly within London Clay, was excavated first to familiarise the crews and create more working space for the large sprayed concrete lining plant operations before breaking out through the shaft diaphragm wall for the eastbound cavern. The primary excavation and spraying plant were proved during this work and training was given to the crews by the suppliers and manufacturers of the plant.

The invert and crown joint connections for the lattice girders and steel-reinforcing bars on the first side-drift to the adjacent enlargement proved challenging to construct (see Figure 5) with some remedial works involving the breaking back of previously sprayed concrete proving necessary. The acute angle of each joint proved difficult to excavate and spray accurately in the close confines of the side-drift. Lessons learnt from the first side-drift in the eastbound tunnel led to a series of improvements in joint preparation that were quickly and successfully implemented in the subsequent double side-wall drift sections of the eastbound and westbound caverns.

Average tunnelling rates achieved for the cavern elements were $0.6-1.7 \mathrm{~m} / \mathrm{d}$

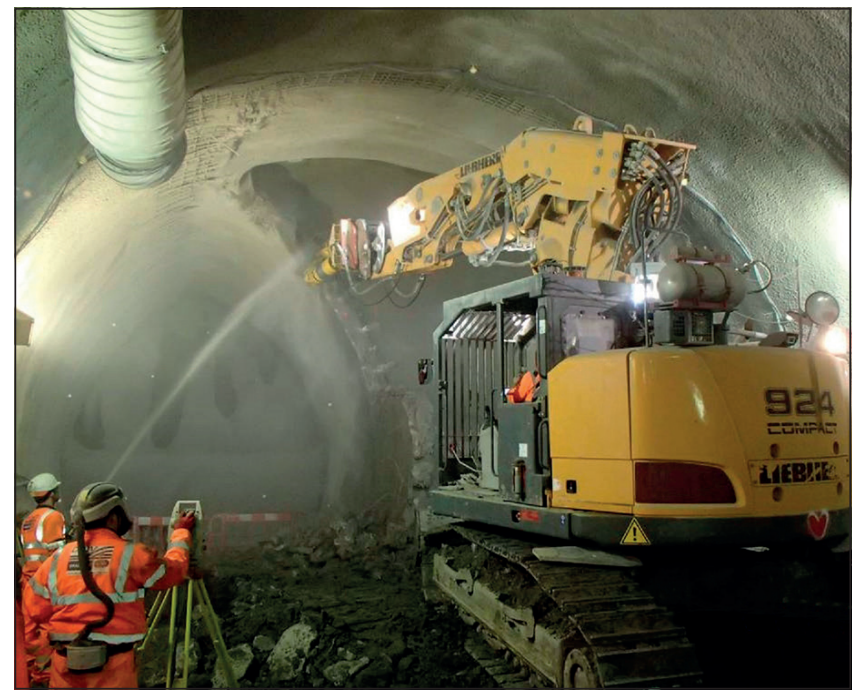

Figure 5. Removal of temporary side-drift side-wall in eastbound cavern of Stepney Green cross-over 


\subsection{Design development during primary lining}

To improve the constructability of the design, the following early changes were agreed and implemented on site.

- Bench excavation rounds for side-drift and enlargement were increased to $2 \mathrm{~m}$ to improve the speed of ring closure.

- Lattice girders were removed from all temporary side walls to minimise handling and erection risks and improve the quality of the sprayed concrete lining.

- Alternate lattice girders were removed from the primary sprayed concrete lining main outer shell to provide girders at $2 \mathrm{~m}$ centres.

- The P2 layer (comprising bar reinforcement but no steel fibres) for invert, bench and top heading was constructed directly after the P1 layer invert in $2 \mathrm{~m}$ long sections to minimise mesh lap joints and improve the quality of the sprayed concrete lining.

- The P2 mesh in the main outer sprayed concrete lining shell at the crown and invert of the side-drifts was left exposed for $1 \mathrm{~m}$ to enable a better lap connection later during the enlargement construction.

\subsection{Secondary lining}

The secondary lining was constructed in various stages after the four TBMs had passed through the caverns, but mainly during the dismantling of the two TBMs at Farringdon.

Water ingress was expected through the primary lining of the bottom half of the westbound cavern and westbound launch adit due to the highly permeable Lambeth Group. The design therefore specified a polyvinyl chloride (PVC) waterproof membrane and cast in situ steel-bar-reinforced concrete secondary lining, which extended from invert to shoulder level (Figure 6).

The upper sections of the caverns were expected to be dry and so a sprayed membrane with a sprayed secondary lining was selected. The extension of the PVC sheet membrane avoided intensive

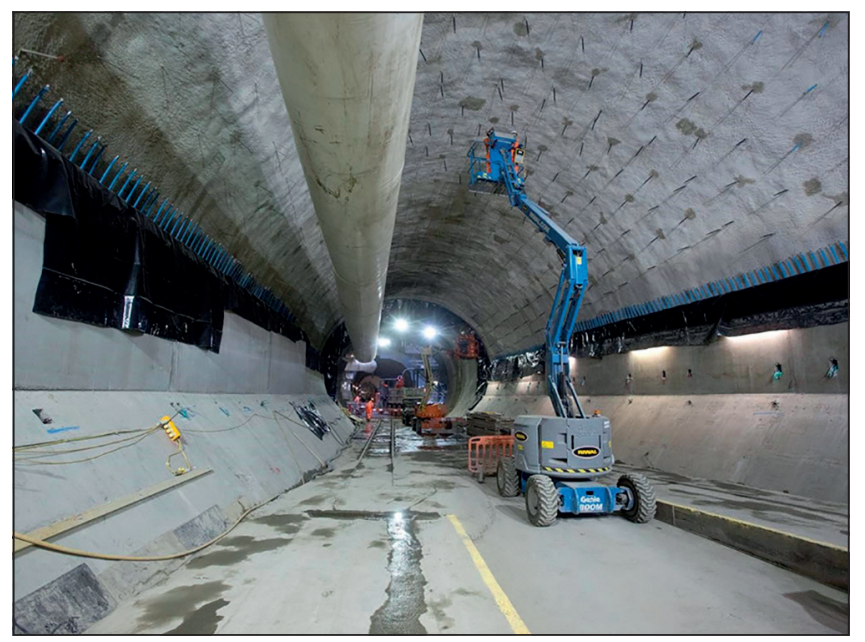

Figure 6. Stepney Green westbound cavern was waterproofed from invert to shoulder level with a PVC sheet membrane and a cast in situ steel-bar-reinforced concrete secondary lining injection in the primary lining to facilitate application of the sprayed membrane.

\section{Whitechapel caverns}

Construction of the Whitechapel cross-over was part of the Whitechapel station contract, which was undertaken by a Balfour Beatty, Bemo Tunnelling, Morgan Sindall and Vinci Grand Projects (BBMV) joint venture. Construction started in 2011 and was completed early in 2017. The cross-over is located just to the west of the station.

Most of the cross-over excavations took place in London Clay with the underlying Lambeth Group located just below the tunnel invert. A $2-3 \mathrm{~m}$ thick sand layer was, however, encountered in the invert of the eastbound cavern. The stratigraphy in the Whitechapel area was such that excavation of the caverns required the Lambeth Group, comprising clays and various sand structures such as pockets, lenses and channels, to be depressurised.

The major challenge was to develop a scheme of probe drilling and depressurisation from within the tunnels that could identify sand structures and manage confined water reliably at the same time as allowing tunnel excavation works to proceed without major disruption. Owing to the success of the depressurisation ahead of excavation, no water was encountered during the works.

\subsection{Westbound excavation sequence and ground support}

The westbound cavern is trumpet-shaped with an initial width of $11.4 \mathrm{~m}$ and a height of $10.9 \mathrm{~m}$ enlarging to a final width of $17.2 \mathrm{~m}$ and height of $14 \mathrm{~m}$. The total cavern length is approximately $35 \mathrm{~m}$. It is the largest sprayed concrete lining tunnel ever built in London Clay. Geological conditions and the cavern size led to the use of double side-drifts with excavations carried out in six stages, as shown in Figure 7.

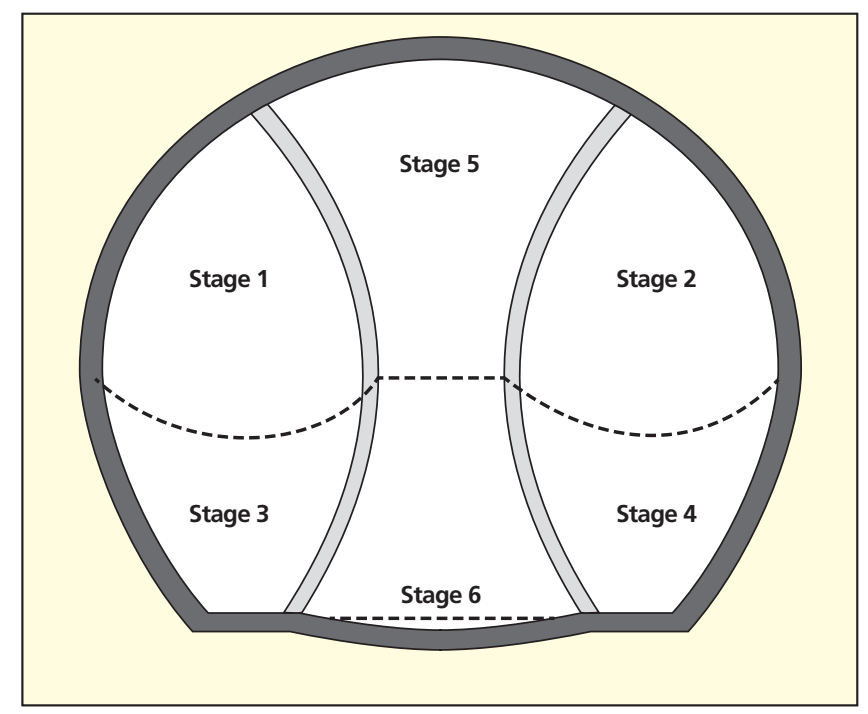

Figure 7. Excavation stages of Whitechapel westbound cavern 
Excavation was based on the Lasershell technique, which has been adapted for large and multi-stage excavations. Its most prominent feature is the inclined and domed excavation face, which improves face stability and provides overhead protection for the workforce. The advance length was $1 \mathrm{~m}$ for each stage with full ring closure. All stages were excavated to full length with a thickening applied before the start of the next stage.

The design thickness of the primary lining increased with the size of the cavern, from $525 \mathrm{~mm}$ to $600 \mathrm{~mm}$ at axis level for the side-drifts and from $725 \mathrm{~mm}$ to $800 \mathrm{~mm}$ in the crown of the central enlargement. The primary lining generally increased in thickness towards the cavern crown and invert, and at connections with the tunnel side-drifts. A $400 \mathrm{~mm}$ thick secondary lining was used throughout.

The westbound cavern was constructed between October 2013 and May 2014 on a $24 \mathrm{~h} / 7 \mathrm{~d}$ shift pattern. The average tunnelling rates achieved for the cavern elements were $0 \cdot 8-3.6 \mathrm{~m} / \mathrm{d}$. Figure 8 shows the full size of the westbound cavern following completion, with the westbound launch chamber on the left and the cross-over tunnel on the right.

\subsection{Eastbound excavation sequence and ground support}

The eastbound cavern adopted a different excavation approach, with construction taking place from the largest to the smallest tunnel cross-section. The revised tunnel construction sequence arose from the fact that construction of one of the station shafts coincided with the eastbound cavern works. A bypass tunnel around the shaft was constructed to minimise disruption to the shaft works and provide independent access to allow the contractor to excavate and construct the eastbound running tunnel, the eastbound cavern, the westbound cavern and the cross-over.

Figure 9 provides an overview of the various cavern excavation stages. The first was the cross-over tunnel, which was constructed from the westbound cavern (stage 1). The $44 \mathrm{~m}$ long section of the eastbound running tunnel was then excavated by constructing a pilot tunnel (stage 2), which was subsequently enlarged (stage 3 ). This was followed by excavation of the final tunnel invert profile (stage 4), resulting in an oval shape. The final stage (stage 5) involved widening the oval with a single side-drift to achieve the final eastbound cavern profile (Figure 10).

The eastbound cavern was constructed between February and August 2014 on a $24 \mathrm{~h} / 7 \mathrm{~d}$ shift pattern. Average tunnelling rates achieved for the cavern elements were $0.9-4.0 \mathrm{~m} / \mathrm{d}$.

\subsection{Design development during primary lining}

The numerous changes to excavation sequences proved a major challenge for both the designer and the contractor. This was due to the many interdependencies between the various tunnel headings (up to three at one time) and the adjacent contracts.

One of the most significant changes was the decision to construct a bypass tunnel around the station shaft. This required both a design on its own and a complete redesign of the eastbound cavern and eastbound running tunnel linings.

A further development was the successful management and control of the excavation profile using total stations and specialist software developed to compare the actual profile against design

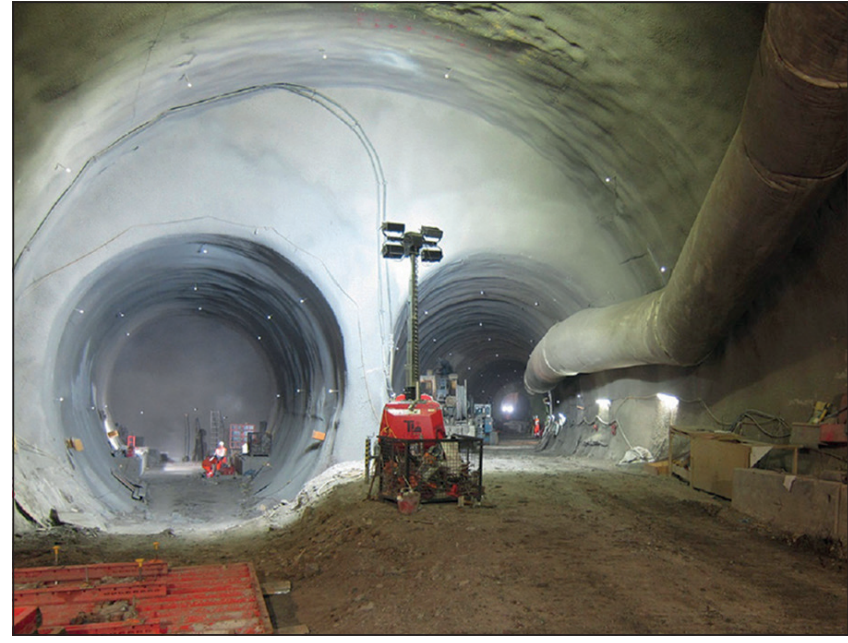

Figure 8. Completed stage 6 excavation of the larger end of the Whitechapel westbound cavern, showing tunnel boring machine launch chamber (left) and cross-over tunnel (right)

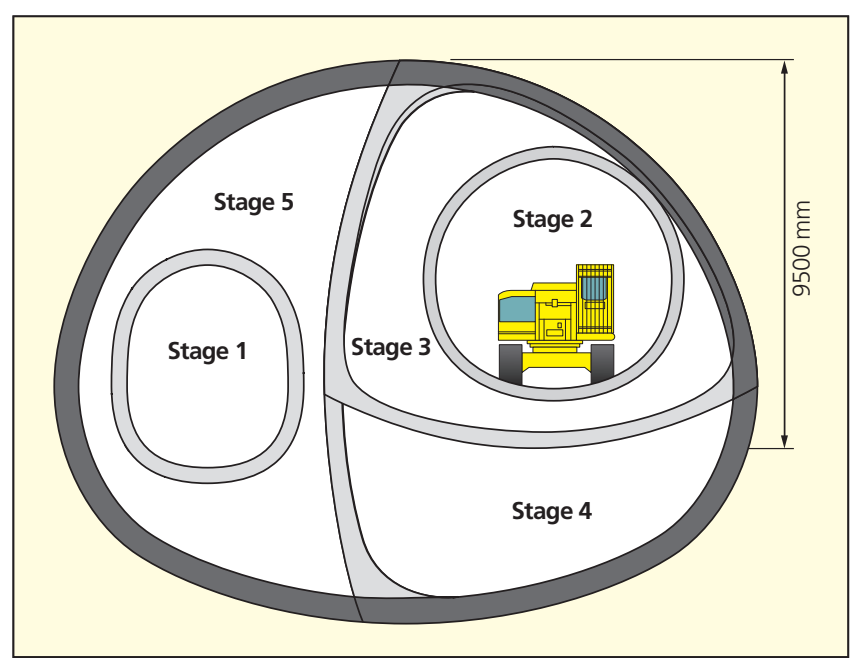

Figure 9. Excavation stages of Whitechapel eastbound cavern

profile. This approach negated the need for profile control using lattice girders.

\subsection{Secondary lining}

The secondary lining at Whitechapel caverns was constructed in a similar manner to the Stepney Green caverns. A waterproof sheet membrane and cast in situ concrete lining was used in the invert up to around $1.5 \mathrm{~m}$ below axis level, with a sprayed waterproof membrane and sprayed concrete lining above.

Furthermore, the decision to combine construction of the secondary lining invert with the first-stage track concrete through the caverns and running tunnels led to overall programme savings. The contractor was able to incorporate significant areas of track construction that would otherwise have been completed by followon contractors. 
Civil Engineering

Volume 170 Issue CE5
Crossrail project: use of sprayed concrete tunnel linings on London's Elizabeth line

Coughlan, Diez, Comins and Stärk

\section{Health and safety}

All sprayed concrete lining work was stopped on the project following the tragic death of a worker at Fisher Street in March 2014 as a result of a large fallout of freshly sprayed concrete from the crown of the tunnel. This incident highlighted the particular danger of fallouts and all contractors set about improving their safety control systems, including

- the establishment, management and control of exclusion zones during and after spraying concrete

- dedicated full-time supervision and guarding of exclusion zones, control of access into neighbouring work areas, and use of barriers, warning signs and closed-circuit television systems

accurate logging and analysis of all fallout events to establish cause and effect remedial measures

- clear communication of all hazards and controls to staff and workforce before and during shifts

- clear lines of communication between management and operatives using information boards, briefings, forums and lessons learnt workshops
- scheduled plant preventative maintenance, pre-use inspections, competency assessments and further on-the-job training

- concrete sampling and testing procedures, in particular for strength development, throughout all stages of the construction of the sprayed tunnel linings.

Crossrail has released a best practice guide for sprayed concrete lining exclusion zone management which covers the above points in more detail (Crossrail, 2016).

\section{Key lessons learnt}

\subsection{Design}

- The complexity of the design responsibility matrix led to complicated interfaces between different design consultants and lengthy processes in order to gain approvals and compliance. The establishment of clear divisions of design responsibilities and a reduction in the number of parties involved on future projects would lead to more optimal and economical sprayed concrete lining design solutions.

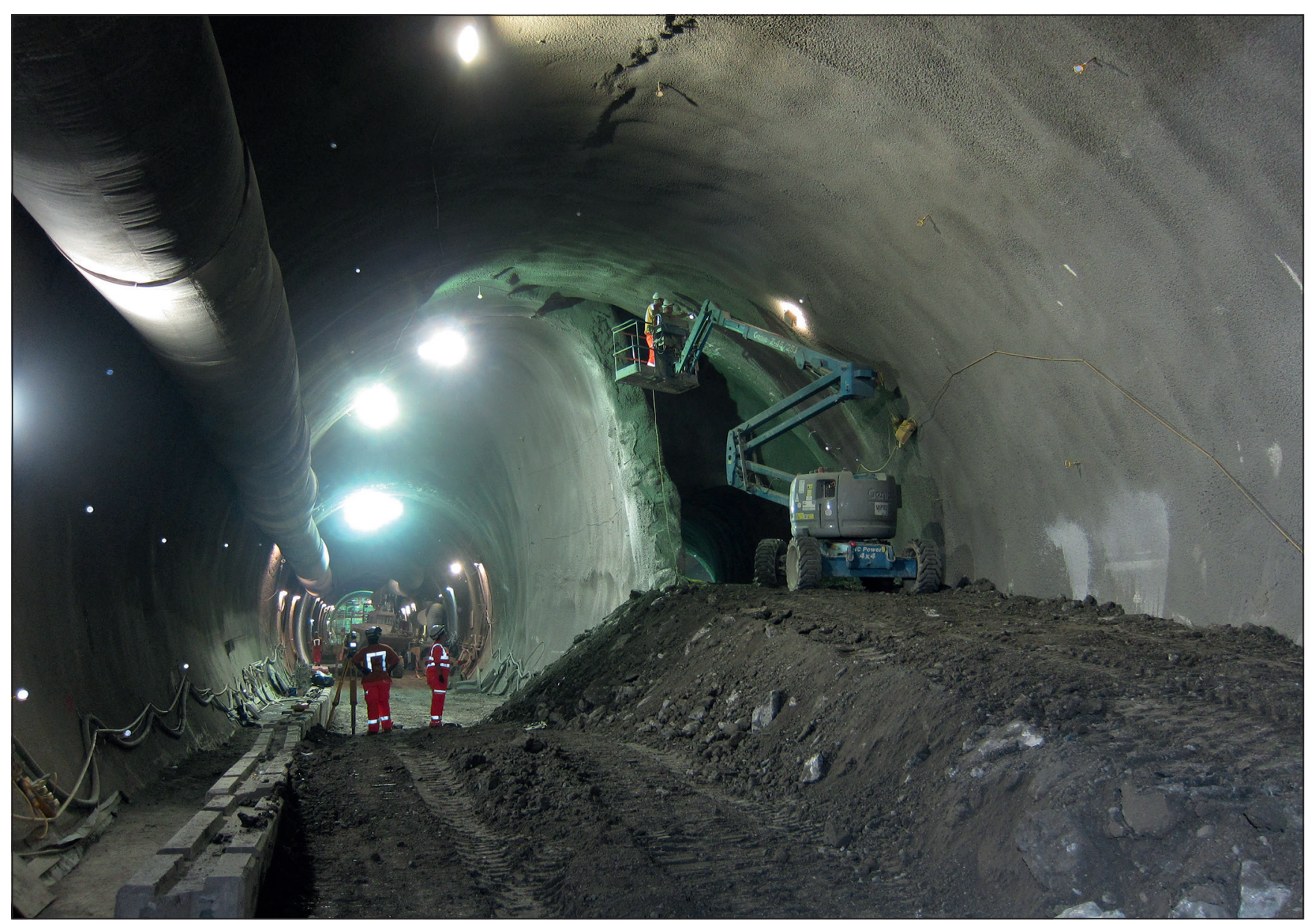

Figure 10. Final excavation stage of Whitechapel eastbound cavern 
Further research and development is required into the use of sprayed waterproofing products to ensure the bond strength with concrete can be relied upon in the long term to allow full composite action of the linings to be considered in future sprayed concrete lining designs.

- Maintaining the profile and tolerance of thin layers of shotcrete has proved challenging and therefore the tolerances for each sprayed layer should be reviewed and the number of layers minimised. Traditional use of profile bars to control the accuracy of final profiles has proved successful in conjunction with appropriate selection of working 'targets' to control spraying. There has been some success with the use of 'semiautomated' application of layers with equipment such as the Atlas Copco Logica system, but this requires careful set-up and control.

- During tunnelling, comprehensive displacement measurements were taken in-tunnel, within the ground and at the surface, resulting in a large database covering more than 4 years of tunnel construction and ongoing design. Such data are rarely used to further review design assumptions on such long-lasting projects and as a result a great opportunity for design and construction improvement is lost.

- Fire testing of sprayed concrete lining materials incorporating typically $2 \mathrm{~kg} / \mathrm{m}^{3}$ of polypropylene fibres indicated compliance with the Eureka fire profile with and without the inclusion of steel fibre reinforcement and profile bars. This led to the opportunity for the incorporation of polypropylene fibres within the secondary lining and the elimination of a further surface fireproofing layer with its inherent requirements to prepare surfaces for receiving sprayed linings and to accurately apply a thin layer and control the final profile.

\subsection{Construction}

During the course of the primary and secondary lining works, a series of lessons learnt workshops were held by the team.

For the primary and secondary linings, the main conclusions were as follows.

- Minimise manual work where personnel might enter the exclusion zone at the face; monitor early strength to control relaxation of an exclusion zone around new sprayed lining.

- Promote fully mechanised work.

- Provided good shape control can be maintained by other means, remove lattice girders from the design due to manual handling, working at height and so on.

- Replace bar reinforcement with steel fibres where possible to reduce risk of shadowing, voids and so on. Review the acceptable size of reinforcement, in particular where sprayed lining is to be applied above the tunnel axis. A lower dosage of accelerator may be appropriate in invert and cast areas.

- Avoid tight corners in the sprayed concrete lining profile (e.g. temporary side-wall junctions with main outer lining shell) as they are difficult to excavate and spray accurately.

- The use of $2 \mathrm{~m}$ advances for bench and invert allows better access for excavation and spraying.

- Minimise construction joints.
- Emphasise the importance of preparatory works to wet down and clean substrates from dust/rebound to ensure good bond between sprayed concrete lining layers. Undertake routine testing of layers to identify potential delamination between layers.

With regards to waterproofing, the following were the key lessons learnt.

- For sprayed membranes, two-pass applications with 3-4 mm wet film thickness in each pass proved more efficient than a one-pass application with 7-8 $\mathrm{mm}$ wet film thickness.

- Damp areas on the regulating layer surface need to be mitigated by the application of grout injection or other suitable drainage solutions to avoid blistering through the curing membrane. The substrate must be fully dried before applying the membrane.

- Depending on the curing conditions, there is usually a $2-3 \mathrm{~mm}$ thick shrinkage for an $8 \mathrm{~mm}$ wet film thickness membrane, leading to dry patch thickness of 5-6 mm.

- Tunnel ventilation is critical during the membrane curing process. Insufficient ventilation could lead to the accumulation of moisture behind the uncured membrane, delaying the curing process.

- Depressurisation helps keep the regulating layer substrate sufficiently dry to allow the application of sprayed waterproofing membranes.

\section{References}

Black M (2017) Crossrail project: managing geotechnical risk on London's Elizabeth line. Proceedings of the Institution of Civil Engineers - Civil Engineering 170(5): 23-30, http://dx.doi.org/10.1680/jcien.16.00024.

BSI (2004) BS EN 1992-1-1: 2004 Design of concrete structures. General rules and rules for buildings. BSI, London, UK.

BSI (2005) EN 14487-1:2005: Sprayed concrete. Definitions, specifications and conformity. BSI, London, UK.

Crossrail (2007) Information Paper D23: Sprayed Concrete Linings. Crossrail, London, UK.

Crossrail (2016) Best Practice Guide: SCL Exclusion Zone Management. Crossrail, London, UK

Crossrail (2012) C121-MMD-Z4-RSP-CR001-00001: Materials and Workmanship Specification Sprayed Concrete Linings KT20. Crossrail, London, UK.

Crossrail Act 2008. Chapter 18. Her Majesty's Stationery Office, London, UK.

EC (European Community) (1996) Council Directive 96/48/EC of 23 July 1996 on the interoperability of the trans-European high-speed rail system. Official Journal of the European Union L235: 6-24.

EC (2008) Directive 2001/16/EC of the European Parliament and of the Council of 19 March 2001 on the interoperability of the trans-European conventional rail system. Official Journal of the European Union L110: 1-27.

Gakis A, Salak P and St. John A (2015) Innovative geotechnical risk management for SCL tunnels. Proceedings of the Institution of Civil Engineers - Geotechnical Engineering 168(5): 385-395, http://dx.doi. org/10.1680/jgeen.14.00070.

Linde-Arias E, Harris D and Davis A (2015) Depressurisation for the excavation of Stepney Green cavern. Proceedings of the Institution of Civil Engineers - Geotechnical Engineering 168(3): 215-226, http://dx.doi.org/10.1680/ geng. 14.00061.

St. John A, Barker J, Frost S and Harris D (2017) Crossrail project: a deep-mined station on the Elizabeth line, London. Proceedings of the Institution of Civil Engineers - Civil Engineering 170(5): 47-56, http:// dx.doi.org/10.1680/jcien.16.00011. 